\title{
Correlation of MOOC Students' Behavior Patterns and Their Satisfaction with the Quality of the Course
}

\author{
Galina Mozhaeva \\ Institute of Distance Education \\ Tomsk State University \\ Tomsk, Russia \\ mozhaeva@ido.tsu.ru
}

\author{
Daria Maslova \\ Institute of Distance Education \\ Tomsk State University \\ Tomsk, Russia \\ da_maslova@ido.tsu.ru
}

\author{
Kristina Yakovleva \\ Institute of Distance Education \\ Tomsk State University \\ Tomsk, Russia \\ kiyakovleva@ido.tsu.ru
}

\begin{abstract}
The article presents the results of the study on the patterns of behavior of massive open online courses (MOOCs) learners in the context of motives to the learning, set criteria of quality, and also the engagement rate. Within the research the data collected on learners enrolled in online courses of Tomsk State University on the online platforms Courcera, Lectorium and National Open Education Platform was classified and analyzed. It allowed us to define the students' patterns of behavior, to reveal the goals of learning on MOOC, social and demographic characteristics of the students, and also the quality criteria of the courses set by the students. As a result of data processing, a correlation between the above-mentioned parameters was found.
\end{abstract}

Keywords: online learning, learning motivation, teaching, online course, learners, students, online learning support, automation of online course student support, virtual learning assistant, student behavior patterns, MOOCs

\section{INTRODUCTION}

The agro-industrial complex (AIC) in general and the dairy One of the main problems in the field of online education is the low completion rate of courses, which is about $5 \%$ at average [1]. Researchers in the field of education note that completion is directly dependent on the learning engagement rate of learners, which is reflected in their behavior patterns $[2,3]$.

The study related to factors influencing on the engagement of learners with different learning behavior patterns contributes to the formation of an optimal model for MOOC learners support. In this regard, it is necessary to identify behavior patterns in the context of motives for learning, the socio-demographic characteristics of learners, MOOCs quality criteria of learners. The correlation between the behavior patterns of learners and their satisfaction with the quality of MOOCs could also contribute to understanding the ways of influencing on the rate of engagement.

\section{THE LiterAture REVIEW AND THE METHODS OF THE STUDY}

\section{A. The literature review}

The MOOC learners' engagement can be defined and measured differently, as well as its causing factors. The specialists note that the engagement of learners is defined by the criteria reflecting the level of the student's attention to the course's content. These criteria are based on the data of learners' behavior. Such criteria were offered in 2014 by 4 scientists: A. Anderson and J. Lescovic from Stanford University, and D. Huttenlocher and J.Kleinberg from Cornnel University. They conducted the research on the engagement rate of MOOCs' learners and suggested their own engagement taxonomy [3]. Russian scientists, as usual, follow the offered criteria [16, 17]. The percentage of the watched video lectures and the completed assignments became the basic criteria used for the estimation of the engagement rate. Today, the given criteria are used for analytics in many universities around the world.

Based on the data analysis on user's behavior according to basic criteria, the scientists of Cornell and Stanford Universities defined the behavior patterns of MOOC learners. According to the engagement level in the learning process (from the highest to lowest), the following types were defined: All-rounders, Viewers, Solvers, Collectors, Bystanders [3]. Anderson, Lescovic, Huttenlocher and Kleinberg proved that 
the learners' engagement is measurable and manifests itself behaviorally.

The scientists Wenzheng Feng, Jie Tang and Tracy Xiao Liu from Tsinghua University also contributed in the research on the engagement, having published the results of the research on the connection between the social and demographic characteristics of learners and their engagement rate. They identified the correlation between sex, age, educational background, course subjects and the learners' engagement rate [18]. The results of the Chinese scientists statistically prove the influence of variety of the factors on the engagement rate, which was mentioned in 2014 by Harvard and MIT scientists, who did the accent on the correlation of course's subject and behavior of the learners [4]. Rely on mentioned research, the student behavior characterized by various engagement rate has factors determining it. These factors can be studied and by affecting them we can modify the behavior of the MOOC learners in a preferred way.

Besides, the effect on the engagement of such factor as «the satisfaction of learners with the course» is considered as important in the international community [5]. The quality of the content plays an important role in the decision-making process about the beginning and continuation of study by the learners. According to these criteria, the quality can be evaluated subjectively, having connection with social and demographic characteristics of learners and depending on the behavior pattern.

This research was supported by "The Tomsk State University competitiveness improvement programme" grant (№ 16).

One more aspect influencing the engagement of learners is the organization of learning support, as today there is an urgent problem of self-regulation in online learning [19]. Many learners do not have certain competencies and soft skills, such as time management, ability to build their own educational trajectory, which are necessary for successful completion of the online courses [20]. In this regard, the role of the support by the course team is growing, as it helps to keep learners on the course and bring them to the end of study and certification [6].

To organize the support of online learning educators often build it on a base of electronic moderation model and tutor support model, applying the variety of different tools [7, 8]. Thus, the support tools have a certain evolution linked to the development of technologies. In 2010 forums, blogs and email for support were mainly used [9]. In 2015 the support of learning in social networks started to be actively used [10]. In 2016 appeared precedents of supporting the learners in messengers and chats-bots [11]. Thus, support communication with learners becomes closer to the learners, getting into their personal digital space and competing the communication with friends and relatives [12, 13]. This issue is also interesting from the point of view of forecasting of the evolution of educational communication and search of methods of its optimization.

It is necessary to note that online learning, in particular in the format of MOOC allows us to accumulate enormous volumes of data connected with the behavior of learners. The analysis of these data, in turn, allows us to correct the process of learning and to trace the result of changes. The use of educational analytics with the purpose of increasing the efficiency of educational process is one of the main trends of the last years both in Russian and in the world education [3, $21,22]$ he individualization, personification, digitalization and other trends are directed, first of all, on the increase of the learners' engagement rate. The reason is its impact on complexity of the acquired knowledge and skills and, as a result, the influence on the quality of education $[14,15]$.

Thus, it can be assumed that the satisfaction of the course and its elements, as well as the requirements imposed by the learners on the quality of the course and its elements depends on the learning goals and affect the behavior patterns of MOOC students. This hypothesis is fundamental to this study.

\section{B. The methods of the study}

To conduct the study we applied the following research methods: questioning, data analysis, descriptive statistics, comparative analysis.

Within the present research, a survey of the learners of MOOCs of Tomsk State University was conducted in the period from 23rd September to 7th October 2019. The learners of the following three courses took part in the survey: "Russian language as a tool of successful communication" (the course is presented on the platforms: National Open Education Platform, Lectoruim and Coursera in Russian language), "Psychodiagnostics" (the course is presented on Coursera in two variants: in Russian and in English), "Genius. Talent. Golden Mediocrity" (the course is presented on Coursera in English and on Lectoruim in Russian). The general popularity (the total amount of learners on the given courses of the specified platforms from the launch dates till 07th October 2019) is 76366 people, the number of the surveyed learners are 189 respondents (of them: 152 are learners from Russia, 37 are foreign learners). The confidence probability is $97 \%$; the confidence interval is $8 \%$.

Within the reserach the following objectives were set:

1) To reveal the behavior patterns of learners of TSU MOOCs.

2) To define a profiles of learners of TSU MOOCs.

3) To reveal the learners' goals of study at TSU MOOCs.

4) To reveal the level of learners' satisfaction with the quality of TSU MOOCs as a whole and with separate elements (video lectures, assignments, additional materials, forums organization).

5) To reveal the criteria of quality the learners set for online courses as a whole and for their separate elements (video lectures, assignments, additional materials).

6) To reveal the differences between the goals of learning, the level of satisfaction with a course and its separate elements, and also between the criteria of quality for a course and its elements in the groups of learners with different behavior patterns. 


\section{B. The profiles of learners of TSU MOOCs}

\section{RESULTS}

\section{A. The behavior patterns of learners of TSU MOOCs}

Taking into a count the influence of the course subject on the engagement rate, we took for research MOOCs from close fields related to the humanities (psychology and philology).

To classify the learners by behavior patterns, we used the taxonomy of engagement offered in 2014 [3]. Considering the different data format of the Russian and foreign online platforms, the analytics on learners' active actions was carried out in terms of only two parameters: views of the video lectures and completion of the assignments. According to the taxonomy the MOOC learners are subdivided into the following categories/patterns of behavior:

7) «All-rounders» (complete the majority of assignments, watch all video lectures);

8) «Viewers» (watch all video lectures but hardly ever complete assignments);

9) «Solvers» (complete assignment and hardly ever watch videos or don't watch them);

10) «Collectors» (watch some lectures and partially complete assignments, or don't complete them);

11) «Bystanders» (enroll on a course, but do not watch video lectures and do not complete any assignments).

In view of the low engagement rate of «Bystanders» and the lack of interest in educational communications, the learners of this category didn't participate in the survey. Thus, the research concerns the learners involved in the educational process with the following patterns: «All-rounders», «Viewers», «Collectors» and «Solvers». The learners were classified according to the answers to the questions on views of video lectures and completion of the course assignments. The ratio of respondents according to the behavior patterns is presented at the figure 1 .

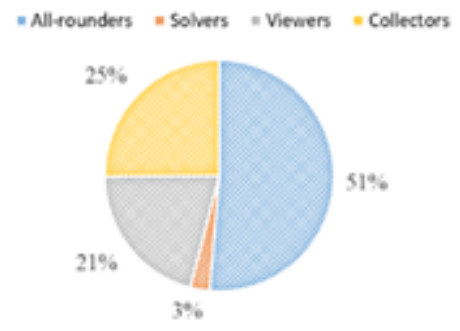

Fig. 1. The behavior patterns of engaged learners

Rely on the data on the behavior patterns, $51 \%$ of learners are classified as "All-rounders", 25\% are "Collectors", "Viewers" are $21 \%$ of respondents and "Solvers" are $3 \%$ of learners.

Further, the social and demographic characteristics of learners, the goals of their learning, and also the satisfaction rate and quality criteria of the courses will be examined within the context of the revealed patterns.
To determine the profiles of learners based on the social and demographic characteristics, the respondents were asked the questions concerning their sex, age, education, and occupation. Let us examine the basic results from the perspective of the behavior patterns.

On the average for all courses participating in the research, $80 \%$ of learners are female, $20 \%$ are male, but among "Collectors" other distribution of genders is observed in comparison with the learners with other patterns: $70 \%$ are women, $30 \%$ are men.

The greatest part among "All-rounders" are people aged 55-65. Their number is estimated at 25\%. Moreover, "Allrounders" are the most widespread category among the group of people of the age 55-65 (other categories such as "Collectors", "Viewers" and "Solvers" contain less than $10 \%$ of the learners at this age).

The categories of learners aged 25-34 and 35-44 with all behavior patterns are approximately equal by the number of representatives (the difference is about 5\%) and together they comprise the general body of all learners (50\% on average). Thus, the given cumulative audiences are widely presented in the category of Viewers (63\%) and to the smaller extent in the category of All-rounders (44\%). Probably, it is connected to the goals of learning, the way of life and generational characteristics.

On an occupation level on the average $50 \%$ of learners have full employment; it is actual for all patterns of behavior. The category of learners with partial employment composes from 20 to 30 percent of learners (least - among All-rounders, most of all - among Collectors). Schoolboys, pensioners and learners in aggregate on the average compose about a quarter of learners.

The behavior pattern according to the level of education corresponds to the data on the occupation. About half of the learners are people with higher education (Bachelor's degree and Master's degree), about a quarter are the learners with a $\mathrm{PhD}$ or who are post-graduate learners.

\section{Learners' goals of study at TSU MOOCs}

As part of the study, learners were asked an open question regarding the purpose of study. According to the results, the main motives for learning were identified (presented in descending order, according to the percentage of mentions by learners):

1) To acquire the knowledge on the subject $-49,7 \%$;

2) Self-development - 31,5\%;

3) Professional development - 12,2\%;

4) Acquaintance with the format of online-learning/with the teaching technique $-3,3 \%$;

5) To obtain a certificate $-2,8 \%$;

6) To test oneself in the context of the subject $-0.6 \%$. 
The satisfaction with the courses is on the level from $93 \%$

Let us consider the main results of the identification of learning goals in the context of behavior patterns. "To acquire the knowledge on the subject" is the most frequent ground for "All-rounders", "Collectors" and "Solvers" (it is true for a half of learners from the given categories) while for the "Viewers" category the ground of "self-development" was in the first place (true for $37 \%$ of learners of the given category). On average, about $30-40 \%$ of learners begin learning with a goal of "self-development" and this number of learners is true for all patterns of behavior. The goal of "professional development" is most often solved through the behavior pattern of a "Viewer" (21\% of "Viewers" have the goal "professional development" while the learners with other patterns choose this motive in $9-14 \%$ of cases).

\section{The level of learners' satisfaction with the quality of TSU MOOCs}

To explore the level of the satisfaction with the quality of an online course as a whole and with its separate elements, the respondents were offered to estimate the video lectures, assignments, additional materials and the course as a whole. The results are presented below in the Table I.

TABLE I. SATISFACTION WITH THE MOOC's QUALITY

\begin{tabular}{|c|c|c|c|c|}
\hline \multirow{2}{*}{$\begin{array}{c}\text { The Subjects of } \\
\text { Evaluation }\end{array}$} & \multicolumn{4}{|c|}{ Behavior Patterns } \\
\hline & $\begin{array}{c}\text { All- } \\
\text { rounders }\end{array}$ & Viewers & Solvers & Collectors \\
\hline Quality of the course & $\%$ & $\%$ & $\%$ & $\%$ \\
\hline yes & 78 & 66 & 60 & 50 \\
\hline rather yes than no & 17 & 32 & 40 & 43 \\
\hline rather no than yes & 4 & 3 & 0 & 4 \\
\hline no & 1 & 0 & 0 & 2 \\
\hline $\begin{array}{c}\text { Quality of video } \\
\text { lectures }\end{array}$ & $\%$ & $\%$ & $\%$ & $\%$ \\
\hline yes & 70 & 53 & 40 & 48 \\
\hline rather yes than no & 27 & 47 & 40 & 39 \\
\hline rather no than yes & 2 & 0 & 0 & 7 \\
\hline no & 1 & 0 & 20 & 7 \\
\hline $\begin{array}{c}\text { Quality of } \\
\text { assessments }\end{array}$ & $\%$ & $\%$ & $\%$ & $\%$ \\
\hline yes & 70 & 45 & 20 & 46 \\
\hline rather yes than no & 28 & 53 & 80 & 41 \\
\hline rather no than yes & 1 & 0 & 0 & 7 \\
\hline no & 1 & 3 & 0 & 7 \\
\hline $\begin{array}{l}\text { Quality of additional } \\
\text { materials }\end{array}$ & $\%$ & $\%$ & $\%$ & $\%$ \\
\hline yes & 62 & 58 & 40 & 46 \\
\hline rather yes than no & 30 & 26 & 60 & 35 \\
\hline rather no than yes & 4 & 3 & 0 & 7 \\
\hline no & 4 & 13 & 0 & 13 \\
\hline $\begin{array}{c}\text { Quality of forum } \\
\text { organization }\end{array}$ & $\%$ & $\%$ & $\%$ & $\%$ \\
\hline yes & 33 & 21 & 20 & 26 \\
\hline rather yes than no & 41 & 42 & 40 & 35 \\
\hline rather no than yes & 10 & 11 & 0 & 15 \\
\hline no & 16 & 26 & 40 & 24 \\
\hline
\end{tabular}

The data shows the dependency of satisfaction with the quality of MOOCs on patterns of listener behavior. The answers "yes" and "rather yes than no" were considered as positive cumulatively, answers "no" and "rather no than yes" were considered as negative cumulatively. to $100 \%$; the least satisfaction with the course is shown by the representatives of the "Collectors" pattern, and the highest one by "All-rounders". Possibly, in this case, the dissatisfaction with the course quality is the factor that leads to the formation of the "Collector" pattern.

The highest level of satisfaction with the quality of video lectures is also characteristic for "All-rounders" (97\%), the least level $(80 \%)$ have the "Solvers". This, on the one hand, is caused by the difference in the goals of interaction with the content of the course by the given groups of learners, and on the other hand, there possibly is a connection with the satisfaction level.

The highest level of satisfaction with the quality of assignments is characteristic for "Solvers"; "Collectors" (87\%) show the minimal level. The given aspect also indicates the connection of an insufficient level of satisfaction with the content and the lower engagement level.

According to the answers of learners, the organization of the learners' communication on the forums is a weak part in the educational process of MOOC. The satisfaction with the given element is from $60 \%$ to $74 \%$. "All-rounders", having the high engagement level, watching all lectures and solving all assignments, are less interested in the external support and motivation to learning, being satisfied with the present format of the work on the forum. It causes the maximum level of satisfaction with the given element among other categories of learners. While about $40 \%$ of learners from the categories of "Viewers", "Solvers" and "Collectors" are not satisfied with the organization of the work on forums and require another approach in comparison with the existing ones. It confirms the urgency of the research in the field of efficiency of student support models.

\section{E. The criteria of quality the learners set for online courses}

The MOOCs listeners' quality criteria was set by the listeners themselves through the answering the open questions of the survey. The answers were processed and generalized according to the similarity of the content. The results of processing the responses (10 the most widespread criteria of each category) presented below (Table II). 
For all the behavior patterns the following quality criteria are most often found: "the information is of interest, is thought-provoking"; "usefulness of the information, applicability to practical work"; "a fascinating, understandable, concise way of presenting"; "urgency and novelty of the content". "The competent and structured way of presenting the material" is important for "All-rounders" and "Viewers" as well as "the formation of new knowledge and skills during the learning". "The possibility to build individual educational trajectories" is important for "Solvers". The criteria "to gain independence/reach their goals" is crucial for "Collectors". In addition, the representatives of the given category of learners appreciate "a variety of forms of the content, the convenience of interaction with it".

The basic criteria of video lectures quality for learners are: "methodically competent construction of educational process"; "conciseness /brevity"; "fascination and availability of the presentation"; "clear speech, good articulation, competent presenter's speech"; "high-quality content (urgency, reliability, completeness)"; "quality of video"; "visualization". "The subtitles/texts/additional materials" are also important for "Viewers". "Solvers" appreciate "an abundance of examples". "Collectors" find important not only the quality of the video but also the sound.

The most widespread criteria for quality evaluation of assignments by all learners are: "the relevance to video lectures and additional materials of the course"; "comprehensibility"; "clearness and correctness of instructions"; "learning something new through an assignment"; "skill formation applicable in practical work"; "conciseness (maximum effect for minimum time)"; "are interesting, require thinking, efforts"; "relevance of the level of complexity to the level of readiness of the audience"; "help to practice the material". "All-rounders" also evaluate "the competence of the teacher who composed the assignment". "Viewers" consider "the possibility to express their opinion" and also "a creative approach" as important. "Solvers" value "a variety of forms of assessment". "Wide coverage of the studied topic and the depth of formed knowledge" are important for "Viewers" and "Collectors". "Solvers" and "Collectors" pay attention to" the urgency of assignments".

The basic criteria for the quality evaluation of additional materials of a course by the learners of all patterns are: "availability"; "wide coverage of the studied topic", "depth of formed knowledge"; "practicality (possibility to apply the material in practice)"; "interest"; "compliance with the course purposes and plan"; "reading format". "All-rounders" and "Viewers" also consider important such criteria as "completeness" and "the relevance to the basic materials of the course, but not duplication". "Viewers", "Solvers", and "Collectors" value "illustrativeness and visualization of the material". "Solvers" note as criteria "the scientific character", "reliability"; "novelty, urgency"; "a variety of formats"; "the contribution of the author to the selection of material".
Let us consider the quality criteria to MOOCs as a whole and to the courses elements (video lectures, assignments, additional materials) within the behavior patterns of learners. 
depends on the goals of learning, the satisfaction with the quality of the course, and also on social and demographic characteristics. But there is a debatable question: what is primary - the behavior of learners or the course content if it satisfies the needs and the criteria of quality set by the learners? To answer this question, we continue the research connected to the application of different models and tools for the support of MOOCs' learners. Within the new research we try to identify the effect of learners support on their behavior patterns. Today, the research in the field of pedagogical design considering the design of a course on the basis of the data on the requirements and preferences of the learners are also urgent. The data presented in the given article can be used in research and applied in practice in the field of online learning.

\section{REFERENCES}

[1] H. Khalil, M. Ebner, "MOOCs completion rates and possible methods to improve retention," A literature review. World Conference on Educational Multimedia, Hypermedia and Telecommunications, 2014, pp. 1305-1313.

[2] K. Swan, "Relationships Between Interactions and Learning in Online Environments," The Sloan Consortium, 2004, [online] elc.fhda.edu, Available at: http://elc.fhda.edu/dev_workshop/docs/interactions.pdf [Accessed 1 Sep. 2019].

[3] A. Anderson, D. Huttenlocher, J. Kleinberg, J. Leskovec, Engaging with Massive Online Courses, [online] Cs.stanford.edu. Available at: https://cs.stanford.edu/people/jure/pubs/mooc-www14.pdf [Accessed 1 Sep. 2019], 2014.

[4] A. Ho, I. Chuang, J. Reich, C. Coleman, HarvardX and MITx: Two Years of Open Online Courses Fall 2012-Summer. [online] Available at SSRN: https://ssrn.com/abstract $=2586847$ [accessed 3 Sep. 2019], 2014.

[5] H. Khalil, M. Ebner, "How satisfied are you with your MOOC?," A research Study on Interaction in Huge Online Courses. In proceedings of the World Conference on Educational Multimedia, Hypermedia and Telecommunications 2013, pp. 830-839.

[6] T. Bates, "What's right and what's wrong about Coursera-style," MOOCs Online learning and distance education resources [online], 2012, tonybates.ca. Available at: https://www.tonybates.ca/2012/08/05/whats-right-and-whats-wrongabout-coursera-style-moocs/ [Accessed 1 Sep. 2019].

[7] Z. Berge, e-Moderating: the key to teaching and learning online. Distance Education. [online], 2013, researchgate.net Available at: https://www.researchgate.net/publication/263488500_e-

Moderating_the_key_to_teaching_and_learning_online/stats/ [Accessed 1 Sep. 2019].

[8] Sites.google.com/site/tutorsoprovogdenie (2013). Tutoring Technique.

[9] [online] sites.google.com/site/tutorsoprovogdenie Available at: https://sites.google.com/site/tutorsoprovogdenie/tema-2 [accessed 5 Sep. 2019].

[10] S. Mak, R. Williams, J. Mackness, "Blogs and Forums as Communication and Learning Tools in a MOOC," Proceedings of the 7th International Conference on Networked Learning, ISBN 978-186220-225-2, 2010, p.275-284.

[11] M.A. AbdelAziz, "Proven Methods to Enhance e-Learning Process Using Social Media (Materials, Interaction, and Competitive Advantage)," International Journal of e-Education, e-Business, eManagement and e-Learning, 2015, 5. 40. 10.17706/ijeeee.2015.5.1.4046.

[12] C. Holotescu, MOOCBuddy: a Chatbot for personalized learning with MOOCs. [online], 2016, researchgate.net Available at: https://www.researchgate.net/publication/304037510_MOOCBuddy_a_ chatbot_for_personalized_learning_with_MOOCs [Accessed $1 \mathrm{Sep}$. 2019].
Relying on the reserach data, we claim that the behavior of MOOCs' learners, characterized by different engagement rate, 
[18] G. Mozhaeva, V. Dyomin, O. Babanskaya, U. Zakharova, "MOOC quality evaluation system: Tomsk state university experience," LNCS, vol. 10254, 2017, pp. 197-202.

[13] M. Coomey, J. Stephenson, "Online learning: It is all about dialogue, involvement, support and control," According to the research. Teaching and Learning Online: Pedagogies for New Technologies, 2001, researchgate.net Available https://www.researchgate.net/publication/239587885_Online_learning_I t_is_all_about_dialogue_involvement_support_and_control__According_to_the_research [Accessed 1 Sep. 2019].

[14] C. Roddy, D.L. Amiet, J. Chung, C. Holt, L. Shaw, S. McKenzie, F. Garivaldis, J.M. Lodge, M.E. Mundy, "Applying Best Practice Online Learning," Teaching, and Support to Intensive Online Environments: An Integrative Review. Front. Educ., 2017, 2:59. doi: 10.3389/feduc.2017.00059.

[15] Issuu.com (2018). A Guide to Quality in Online Teaching and Learning. [online] issuu.com Available at: https://issuu.com/fleksibel_utdanning_norge/docs/quality_education_net version [Accessed 1 Sep. 2019].

[16] W.R. Kilfoil, Moving beyond the hype: A contextualised view of learning with technology in higher education, 2015

[17] T. Bystrova, V. Larionova, E. Sinitsyn, A. Tolmachev, MOOC learning analytics as a tool for predicting learners' success. [online], 2018, Vo.hse.ru.

$$
\text { Available }
$$

https://vo.hse.ru/data/2018/12/12/1144863782/08\%20Bystrova.pdf

[Accessed 1 Sep. 2019].
[19] W. Feng, J. Tang, T. Xiao Liu, Understanding Dropouts in MOOCs [online], 2019, Available at: http://keg.cs.tsinghua.edu.cn/jietang/publications/AAAI19-Fengdropout-moocs.pdf [accessed 3 Sep. 2019].

[20] E. Pogorskiy, J.F. Beckmann, S. Joksimovic, V. Kovanovic, R. West, "Utilising a Virtual Learning Assistant as a Measurement and Intervention Tool for Self-Regulation in Learning," 2018 IEEE International Conference on Teaching, Assessment, and Learning for Engineering (TALE), 2018, pp. 846-849. https://doi.org/10.1109/TALE.2018.8615130

[21] I.Y. Malkova, O.M. Babanskaya, U.S. Zakharova, E.V. Ryltseva, G.V. Mozhaeva, K.I. Tanasenko, "Identifying Competencies for taking online courses successfully," INTED 2018 : conference proceedings 12th International Technology, Education and Development Conference, 5-7 march 2018, Valencia. [Valencia], 2018, pp. 0575-0581.

[22] V. Larionova, MOOC evaluation algorithms based on educational analytics, 2018, Openedu.urfu.ru.

[23] G. Mozhaeva, G. Krasnova, E-education in the era of digital transformation, 2019. 